\title{
A experiência histórico- cultural de constituição de classe entre os trabalhadores telefônicos do Paraná
}

\author{
The historical and cultural experience of class formation \\ among Paraná telephone workers
}

\section{Ivana Cristina Lima de Almeida*}

\begin{abstract}
Resumo - A década de 1950 ficou conhecida entre os historiadores do sindicalismo brasileiro como a década do chamado "renascimento das lutas urbanas e rurais". No contexto regional do setor de telecomunicações do Paraná, foi ao final dessa década que um grupo de trabalhadores, em circunstâncias econômicas e socioculturais específicas, constituiu-se como classe. Tomando por base o conceito de experiência histórica de E. P. Thompson, esta investigação adentrou no processo de organização sindical dos trabalhadores telefônicos do Paraná com o objetivo de dialogar com as histórias e memórias desses sujeitos. Apoiado em relatórios, publicações, documentos oficiais, atas e aplicação de entrevistas, esse estudo de caso procurou apreender a dinâmica da relação entre a dimensão objetiva das transformações ocorridas e os modos pelos quais os trabalhadores absorveram, (re)elaboraram e vivenciaram culturalmente essa experiência conflituosa, traduzindo-a em ações políticas de e para a classe.
\end{abstract}

Palavras-chave: experiência histórica; cultura; classe trabalhadora; telecomunicações; Paraná.

\begin{abstract}
The 1950s became known among Brazilian historians of trade unionism as the decade of the so-called "rebirth of urban and rural struggles." In the Paraná regional context of the telecommunications industry, it was at the end of that decade that a group of workers, in certain economic, social, and cultural circumstances, constituted themselves as a class. Based on E.P. Thompson's concept of historical experience, this research went in-depth into Paraná telephone workers' process of union organization, with the objective to get acquainted with the stories and memories of these subjects. This case study was supported by various reports, publications, official documents, and meeting reports, as well as interviewing techniques, and sought to grasp the dynamics of the relationship between the objective dimension of the changes that took place and the ways in which workers absorbed, (re)created and lived culturally this conflicting experience, translating it into political action of and for class.

Keywords: historical experience; culture; working class; telecommunications; Paraná.
\end{abstract}

\footnotetext{
* Doutoranda em Sociologia pela Universidade Federal do Paraná e Professora Adjunta da Universidade Positivo do Paraná. Correspondência: Rua Carneiro Lobo, 455/ap. 401 - Água Verde - Curitiba/PR. CEP: 80240-240. Email: <ivanalimadealmeida@gmail.com>.
} 


\title{
Considerações iniciais
}

\author{
Meu enleio é que um tapete \\ é feito de tantos fios que não \\ posso me resignar a seguir um \\ fio só; meu enredamento vem \\ de que uma história é feita \\ de muitas histórias. \\ (Clarice Lispector)
}

Não é possível mergulhar na trama da experiência histórica de constituição da classe dos trabalhadores telefônicos do Paraná no início da segunda metade do século $\mathrm{XX}$, sem sentir-se enredado em uma teia de fios políticos, econômicos, sociais, culturais e ideológicos. Definitivamente não se trata de uma época qualquer no passado. Trata-se de um tempo recentemente vivido por muitos de seus personagens, por intermédio do qual o tempo de vida íntimo confunde-se (e entrelaça-se) com a grande história dos acontecimentos gerais.

O setor de telecomunicações, por sua natureza e especificidade, tem sido um território temido e até evitado pelos que nele não trabalham. Tanto em seus aspectos técnico-organizacionais quanto em seus aspectos político-institucionais, o processo de "comunicação a distância" por vias eletromagnéticas (telégrafo, telefone, rádio, TV e outras) passou a desempenhar, ao longo de sua trajetória, um papel decisivo no tecido socioeconômico dos países mais e menos industrializados.

No Brasil, as telecomunicações foram incorporadas à sociedade na segunda metade do século XIX, quando o governo imperial reconheceu o serviço telegráfico como de grande interesse público, sobretudo quanto ao aspecto da segurança nacional, reservando ao poder central a competência de regulamentação e à administração pública a exploração direta do serviço (ALMEIDA, 2004).

De certa forma, a organização das telecomunicações nessa época fazia parte de um padrão mais geral de exploração da infraestrutura dos fabricantes norte-americanos e europeus. Estes, via de regra, estabeleciam filiais de serviços em países como o Brasil para garantir apenas os troncos mais rentáveis, não se propondo a estabelecer uma rede de comunicação que integrasse os respectivos espaços nacionais.

Essa situação permaneceu inalterada mesmo após a instituição do regime republicano no país. Na verdade, seguindo o propalado "espírito de descentralização" da Carta Constitucional de 1891, cada estado federativo passou a ter direito à própria política para o setor, e vários deles (inclusive o Paraná) reproduziram essa descentralização aos seus municípios. Resultado: até o final dos anos de 1920, quando surgiu a tecnologia do rádio anunciando a libertação do fio, as telecomunicações brasileiras estiveram fatiadas entre as empresas privadas nacionais e estrangeiras e o Estado. 


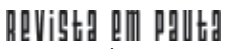

\} A EXPERIÊNCIA HISTÓRICO-CULTURAL - ALMEIDA, I. C. L. \}

DOI 10.12957/REP.2017.30378

Embora a União viesse a retomar, durante o Estado Novo (19371945), a competência para regular o setor e instituir os serviços de telégrafos como sua exclusividade, tal reforma política não se aplicou aos serviços de telefonia, ainda encaminhados por um oligopólio formado por seis empresas estrangeiras, duas das quais exerciam também o controle da venda de equipamentos de telecomunicações no país (ALMEIDA, 2004).

Esse modelo solidamente privado sofreria uma nova orientação constitucional em 1946, pelo menos em relação aos serviços de telégrafos, radiocomunicação e radiodifusão sobre os quais a União consagrou-se como única a regular e explorar diretamente, ou mediante concessão ou autorização a outros. Quanto à telefonia por fio, a responsabilidade federal restringiu-se às áreas interestaduais e internacionais, permitindo às unidades da federação que formulassem a política telefônica em âmbito estadual.

Tais diretrizes vigoraram até a década de 1960, período em que a política de telecomunicações tornou-se objeto de forte mudança jurídica e institucional, ensejada por fatores quantitativos - elevação da capacidade de atendimento e cobertura - e qualitativos - melhoria no sistema de ligações e tarifas - imprescindíveis ao atendimento das comunicações nacionais, internacionais e aos fins militares. Esse processo culminou com a estruturação de um monopólio público vigente até o final dos anos de 1990, quando outra vez alterações governamentais (reprivatização), acompanhadas prévia e posteriormente de novos avanços tecnológicos (introdução dos sistemas digitais em substituição aos sistemas analógicos), voltaram a "revolucionar" o setor.

Mas se, a essa altura, os fatos aqui expostos são historicamente importantes para o entendimento do contexto que tem envolvido, desde suas origens, as telecomunicações brasileiras e, em particular, paranaenses, há algo mais a ser explicado nessas transformações do que capitais, fatores produtivos, leis e mercados. Ainda falta explicar, por exemplo, como, nessa teia de fios socioeconômicos e político-institucionais, alguns homens e muIheres profissionalmente acoplados a essa esfera - como atores de seus dramas e observadores de suas épocas - viram e articularam os seus interesses coletivos.

Em outras palavras, falta explicar como, em um contexto regional próprio, os empregados daquelas companhias foram revelando necessidades, reivindicações e anseios e (trans)formando-se, daí em diante, em força associativa e movimento sindical.

Foi em busca desse processo que o estudo de caso desenvolvido ${ }^{1}$ se enveredou no conceito de experiência histórica de Edward Palmer Thompson (1924-1993) com o objetivo de apreender, no final da década de 1950,

\footnotetext{
${ }^{1}$ As análises desenvolvidas neste artigo são provenientes, em parte, da pesquisa de Mestrado Adeus ao sindicato? O sindicalismo diante das transformações no mundo do trabalho: o caso do setor de telecomunicações no Paraná, de 2004; e, em parte, da pesquisa de Doutorado em andamento na UFPR.
} 


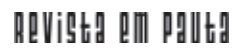

\} A EXPERIÊNCIA HISTÓRICO-CULTURAL - ALMEIDA, I. C. L. \}

DOI 10.12957/REP.2017.30378

a dinâmica da relação entre a dimensão objetiva das mudanças ocorridas e os modos pelos quais os trabalhadores absorveram, (re)elaboraram e vivenciaram culturalmente essa experiência conflituosa, traduzindo-a em ações políticas de e para a classe.

Na escolha desse caminho, o diálogo com as histórias e memórias desses sujeitos apoiou-se na leitura de relatórios e atas de assembleias sindicais do período 1958-1961, nas publicações do Instituto Brasileiro de Geografia e Estatística (IBGE) da década de 1950, em boletins do Dieese de 1959-1961, em documentos oficiais do Ministério do Trabalho e na aplicação de entrevistas entre os anos de 2003 e 2004 a três trabalhadores - identificados como T1, T2 e T3 -, que participaram da organização do Sinttel/PR desde as suas origens.

Dentro das dimensões cabíveis neste artigo, a intenção é discutir, a partir da especificidade do setor de telecomunicações brasileiro daquele momento, o processo histórico de constituição dos interesses coletivos dos trabalhadores telefônicos do Paraná entre 1958 e 1959. Nesta perspectiva, Thompson se torna um interlocutor privilegiado.

\section{Thompson e a experiência histórica como constituinte de classe}

Entre as últimas décadas do século XVIII e as primeiras décadas do século XIX, mais precisamente entre 1780 e 1832, "os trabalhadores ingleses em sua maioria vieram a sentir uma identidade de interesses entre si, e contra seus dirigentes e empregadores" [grifo meu]. (THOMPSON, 1997, p.12). Assim escrevia em agosto de 1963 o historiador inglês Edward Palmer Thompson no Prefácio de sua obra The making of the english working class, na tradução brasileira, A formação da classe operária inglesa" ${ }^{2}$.

A afirmativa de Thompson (1997), decorrente de seus estudos a respeito da classe operária inglesa como agente histórico principal de sua própria formação, abriu na década de 1960 novas perspectivas teóricas e metodológicas para o entendimento da atuação dos trabalhadores no processo de constituição de sua classe. Quando se fala em nova perspectiva teórica, pretende-se dizer com isso que a proposição thompsoniana diverge, dentro do marxismo ao qual se filia, das abordagens estruturalistas ortodoxas (como a de Louis Althusser). Naquela década, a leitura de Louis Althusser (1918-1990) da obra de Marx se difundiu na historiografia britânica, fazendo crescer a aceitação de que a história, conforme aponta o próprio Althusser (1978, p. 70-71 - grifos no original),

\footnotetext{
${ }^{2}$ A obra de E. P. Thompson, The making of the english working class, analisa as origens da classe operária inglesa no período de 1790 a 1832, e foi elaborada em três partes. No Brasil, onde a primeira edição é de 1987, A formação da classe operária inglesa foi publicada em três volumes: A árvore da liberdade, A maldição de Adão e $A$ força dos trabalhadores. Para uma análise detalhada da obra de Thompson, ler: Bryan Palmer (1994).
} 


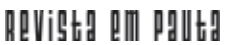

\} A EXPERIÊNCIA HISTÓRICO-CULTURAL - ALMEIDA, I. C. L. \}

DOI 10.12957/REP.2017.30378

é um imenso sistema natural-humano em movimento e o motor da história é a luta de classes. [...] A história é certamente um processo sem Sujeito nem Fim(ns), cujas circunstâncias dadas, nas quais 'os homens' agem como sujeitos sob a determinação de relações sociais, são o produto da luta de classes. Portanto, a história não tem, no sentido filosófico do termo, um Sujeito, mas um motor: a luta de classes.

Essa perspectiva foi considerada estruturalista ortodoxa na medida em que torna a história dependente de contradições estruturais e exclui os sujeitos do processo de mudança social. Além disso, a definição de classe está relacionada aos meios de produção e à posição que o indivíduo assume dentro da estrutura econômica. Portanto, compreende a existência da classe e da consciência de classe como superestrutura condicionada inteiramente à base material da sociedade ${ }^{3}$.

É nesse ponto que a crítica de Thompson (1997, p. 9 - grifos meus) irrompe, principalmente no seio do marxismo althusseriano, para advogar que "a classe operária não surgiu tal como o sol numa hora determinada. Ela estava presente ao seu próprio fazer-se". E argumenta: "Não vejo a classe como uma 'estrutura', nem mesmo como uma 'categoria', mas como algo que ocorre efetivamente (e cuja ocorrência pode ser demonstrada) nas relações humanas"4.

A partir das duas citações acima, somadas a que abre esta discussão, Thompson (1997) revela a sua intenção de desconstruir a ideia de os trabalhadores (ingleses) serem vistos como uma "entidade" receptora das determinações de outra classe que os domina e que os considera inferiores. Pode-se acrescer também, nessa reflexão, a crítica à necessidade de a classe operária ser "guiada" para adquirir consciência de seu lugar subalterno na formação social e de condutora da luta de classes. Em outras palavras, a formação da consciência de e para a classe determinada pela estrutura de produção da sociedade e pelo antagonismo de classe.

E como Thompson rompe teórica e metodologicamente com essa concepção? Sem sair do solo marxiano, Thompson (1997, p. 9) passa a estudar a classe (operária inglesa) como um "fenômeno histórico [grifo original], que unifica uma série de acontecimentos díspares e aparentemente desconectados, tanto da matéria prima da experiência como na consciência [grifos meus]".

Chamo a atenção para cada um dos termos destacados aqui, porque neles estão os elementos teóricos e metodológicos das proposições thompsonianas que marcam a sua ruptura com as noções marxistas ortodoxas.

Então, vejamos. Ao se referir à classe como fenômeno histórico, significa que a classe deve ser entendida como uma formação social e cultural

\footnotetext{
${ }^{3}$ Para maiores detalhes, ver: Louis Althusser (1978).

${ }^{4}$ A crítica de Thompson a esses argumentos encontra-se em: E. P. Thompson (1981).
} 


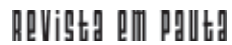

\} A EXPERIÊNCIA HISTÓRICO-CULTURAL - ALMEIDA, I. C. L. \}

DOI 10.12957/REP.2017.30378

constituída por homens e mulheres em suas ações e relações sociais ao longo de um processo histórico, a exemplo do que o próprio Thompson identifica entre os anos de 1780 e 1832 ao estudar os trabalhadores ingleses.

A dimensão histórica introduz no fenômeno classe o conteúdo dialético, apontando transformações, contradições, rupturas, permanências e mediações que devem ser investigadas e apreendidas na prática do agir humano. Por sua vez, quando anuncia que o processo histórico reúne um conjunto de acontecimentos aparentemente díspares e desconectados, Thompson (1997) indica que há, nessa dinâmica, um complexo de visões e de interesses opostos que motivam objetiva e subjetivamente homens e mulheres a agir na formação de classe.

Sendo assim, o fenômeno classe pertence simultaneamente à história econômica, política e cultural. E, se a lógica desse processo é indeterminada (embora cheia de pressões), sua descrição pode e deve ser realizada em termos históricos, ou seja, tanto como resultado da experiência quanto da consciência de homens e mulheres que vivem a sua própria história.

Nesse ponto, Thompson (1997) introduz o conceito de experiência (termo inexistente na ortodoxia marxista) para se referir ao modo pelo qual as pessoas - individualmente ou em um grupo social - experimentam, em suas relações produtivas, necessidades, interesses e conflitos, traduzindoos em respostas mentais e emocionais. Nesse sentido, experiência vinculase à cultura na medida em que, para Thompson (1997), ideias e sentimentos são experimentados por homens e mulheres como normas, valores, formas elaboradas na arte ou nas convicções religiosas e políticas.

E também porque as transformações socioeconômicas são desenvolvidas na e pela cultura, portanto, vividas e percebidas no ser social e na consciência social. Isso significa que a formação da classe é uma experiência histórica de "ser social" (experiência de classe nas relações de produção) e de "consciência social" (consciência de classe experienciada em tempoespaço próprios) que se constitui no processo da existência e da ação humanas. Dessa forma, configura-se aqui uma impossibilidade: o conhecimento do fazer-se da classe (em Thompson, operária inglesa) dissociado das experiências nascidas dos confrontos entre classes em virtude de suas diferenças culturais, políticas e religiosas, entre outras.

Nessa perspectiva, é por meio da experiência que a consciência social se realiza e se expressa como experiência de classe que pode ser examinada e descrita "em suas relações, suas ideias e instituições" (THOMPSON, 1997, p. 12), dentro de um determinado período de mudanças sociais, contextualizado nos momentos históricos específicos a que pertence culturalmente.

Em termos metodológicos, isso exige, para Thompson (1997), articulação entre teoria e empiria para discutir um contexto particular no diálogo analítico entre o econômico e o cultural, entre a história e o social. É dentro 
dessa dinâmica que procuro descrever, a seguir, a experiência histórica de formação de classe dos trabalhadores telefônicos do Paraná entre 1958 e 1959.

\section{Os trabalhadores telefônicos do Paraná e a experiência histórica de e para a classe}

"Porque a associação é necessária para defender os interesses da classe, a exemplo de outras categorias profissionais existentes em nosso Estado" (SINTTEL, 1961 - grifo meu). Assim foi encerrado o discurso de S. B. S. ${ }^{5}$ na primeira assembleia legal instalada para a criação da Associação Profissional dos Trabalhadores em Empresas Telefônicas e Radiotelefônicas do Estado do Paraná, em oito de julho de 1958.

Naquela noite, 46 dos 53 membros fundadores aprovaram por unanimidade os artigos do estatuto-padrão, recomendado pelo Ministério dos Negócios do Trabalho, Indústria e Comércio (Portaria no ${ }^{\circ}$ 126, de 26 de junho de 1958). Aprovaram também os nomes de três colegas - incluindo o de S. B. S. como presidente - para a diretoria e de mais três para o conselho fiscal da associação, conforme correspondência oficial expedida à Delegacia Regional do Trabalho pelo secretário eleito L. V.

Alguns meses antes, durante aqueles períodos em que a indignação parece mover as pessoas no sentido de desafiar as autoridades que normalmente respeitam, S. B. S., então com 48 anos de idade, vivenciou uma experiência definitiva. Ao tocar a campainha em uma casa de Curitiba para realizar a instalação de um telefone, a dona da casa o olhou da janela e, assustada, tentou dispensá-lo dizendo que não tinha esmola para dar. Confundido com um mendigo, um dos instaladores mais antigos da companhia teve a certeza de que a situação dos telefônicos chegava ali ao seu limite.

Era hora de ouvir o colega M. G. M., um espanhol de 45 anos que já havia participado de um movimento de trabalhadores em São Paulo na década de 1940, cujo resultado tinha sido a fundação de um sindicato estadual da categoria. Desde meados dos anos de 1950, o cabista M. G. M. - além de outros cabistas vindos também da capital paulista - já se queixava dos salários baixos e da vida difícil que levavam como empregados da Companhia Telefônica Nacional, no Paraná, onde muitos estavam insatisfeitos, mas tinham medo de reclamar. Para ele, a solução era uma só: a formação de um sindicato.

As primeiras conversas sobre o assunto surgiram no bairro Oficinas, em Curitiba, onde M. G. M., S. B. S., o encarregado de rede G. A., de 31 anos, e o reparador A. C. A., com 41 anos, também moravam:

${ }^{5}$ Os nomes dos trabalhadores do setor de telecomunicações do Paraná serão indicados, neste artigo, por siglas. 
No início, era difícil pra nós formar o sindicato porque nós era completamente leigo a esse negócio de sindicalismo, né? Então, ninguém conhecia. Outros já conheciam isso, como os metalúrgicos, a construção civil... mas nós, não. No meu entender da época, ele [M. G. M.] foi a pessoa que mais incentivou. A experiência dele ajudou a nós formar o movimento aqui. (Entrevista de um dos fundadores do sindicato, aqui identificado como T1 - Trabalhador 1 - grifos meus].

Do bairro para o local de trabalho, a ideia chegava ao depósito da Rua Marechal Floriano com a Brasílio Itiberê, conseguindo aglutinar cerca de dez pessoas "confiáveis", entre empregados da instalação, da construção e da manutenção dos serviços de telefonia. Quase todos também com idade acima dos 35 anos e "tempo de casa" superior a dez anos.

Temendo represálias por parte da empresa, o grupo manteve sigilo. Muitos ainda se lembravam da tentativa frustrada de 1949 quando, ainda nos tempos da Companhia Telefônica Paranaense, por interferência de "empregados que eram do lado de lá, ligados à empresa" (Entrevista T1), foi dissolvido um movimento idêntico com a demissão de todos os envolvidos.

Naquela conjuntura do imediato pós-guerra, não foram poucos os que acreditaram nos ventos da democratização trazidos pela vitória dos aliados contra o nazi-fascismo e pela queda do Estado Novo de Getúlio Vargas, os quais poderiam favorecer a organização da categoria. Todavia, se, de um lado, a época foi propícia ao surgimento de centenas de sindicatos pelo país - de 1945 a 1949, o IBGE registrou um aumento de 19,4\% no número de sindicatos de trabalhadores, passando de 873 para 1.042 (IBGE, 1950) -, de outro, o movimento operário encontrou inúmeras dificuldades para desenvolver-se como luta política. Muitos nem saíram da ideia, como é o caso dos telefônicos do Paraná, abortado pela companhia em seu nascedouro.

Mas, agora, quase dez anos depois, unidos por um "destino que Ihes parecia comum" (Entrevista T3), aqueles empregados mais e menos antigos de casa se convenciam de que a salvação social estava em suas próprias mãos. Os articuladores do novo movimento mostravam-se imbuídos de um espírito de inconformismo com a situação de trabalho e de vida em um momento em que a dissensão estava em alta.

A década de 1950 ficou conhecida entre os historiadores do sindicalismo brasileiro como a década do chamado "renascimento das lutas urbanas e rurais" (ANTUNES, 1995). No segundo Governo Vargas, especificamente em 1953, os reajustes salariais haviam sido muitas vezes conquistados a partir de longas greves e debaixo de forte repressão, como a "Greve dos 300 mil", na qual sete categorias estiveram paralisadas em São Paulo por um mês (ALMEIDA, 2004).

Naquele período, o papel das comissões de fábricas foi decisivo tanto para a formação de uma Comissão Intersindical (CIS), que deu origem ao Pacto de Unidade Intersindical (PUI), quanto para as grandes mobilizações 


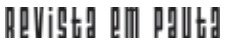

\} A EXPERIÊNCIA HISTÓRICO-CULTURAL - ALMEIDA, I. C. L. \}

DOI $10.12957 /$ REP.2017.30378

subsequentes realizadas pelos "sindicatos oficiais". No entanto, foi a partir do Plano de Industrialização "50 anos em 5", de Juscelino Kubitschek, e do desenvolvimento da indústria automobilística, que se podem notar mudanças no perfil da classe operária e na politização do movimento sindical.

Setores de forte peso na força de trabalho do país, como os de metalurgia, de plásticos, de derivados de petróleo, das estatais e do setor público, passaram a lutar contra os baixos salários, a carestia e a inflação. Além disso, no campo, as Ligas Camponesas, formadas desde 1955, impulsionavam a criação da Confederação Nacional dos Trabalhadores Agrícolas (Contag), exigindo reformas e direitos trabalhistas (ALMEIDA, 2004).

A pressão pela solução dos problemas habitacionais, de saneamento e de saúde trazia à tona o fracasso (ou a ausência) de medidas governamentais adequadas para produzir o mínimo de desigualdades sociais. Junte-se a isso a crise inflacionária do final dos anos de 1950 e o resultado frustrava as expectativas de trabalho e de consumo de bens disponíveis, acionando o estopim dos conflitos sociais, em particular nas áreas urbanas.

No contexto regional do setor de telecomunicações, a necessidade de os trabalhadores recuperarem suas perdas salariais e melhorarem suas condições de vida, aliada ao clima de relativa liberdade existente, impeliuos à organização da categoria. De acordo com o depoimento de um dos fundadores e ex-presidente do sindicato, aqui identificado como T2: "O ambiente político foi um incentivo porque havia uma democracia e a gente tinha a liberdade de formar o sindicato. Havia era as restrições da própria lei, do Ministério do Trabalho, das delegacias regionais, mas na parte da formação não houve obstáculos".

As maiores queixas dos telefônicos de Curitiba se referiam à elevação do custo de vida que, em uma década e meia (de 1943 a 1958), ultrapassou os $150 \%$ sem a contrapartida de reajustes salariais compatíveis. Segundo um estudo do Departamento Intersindical de Estatísticas e Estudos Socioeconômicos (DIEESE, 1961) sobre a segunda metade dos anos 1950, enquanto o lucro bruto da produção industrial elevou-se ininterruptamente, crescendo $76 \%$, e enquanto a produtividade do operário aumentou também ininterruptamente, crescendo $37 \%$ nesse mesmo período, o salário real (ou seja, o poder aquisitivo do operário) sofreu apenas um ligeiro incremento de $18 \%$ entre 1955 e 1958.

Como grande parte dos empregados não qualificados e pouco qualificados da companhia ganhava entre meio e um salário mínimo, e só alguns empregados qualificados recebiam entre dois e três, o número dos que tinham que se conformar com menos de dois salários mínimos era consequentemente muito mais alto. Assim, agregava-se à degradação da renda do trabalhador a natureza do próprio trabalho a que muitos se submetiam:

Quando eu entrei na Companhia [em 1948], me mandaram fazer buraco e implantar poste, né, para serviços gerais. Andei por toda a redondeza. 
Tinha que trabalhar sábado, muitas vezes no domingo e até feriado. A Companhia queria. Eu comecei ganhando meio salário e só bem depois, com mais de seis anos de casa, é que cheguei a um salário. O serviço eu acho que não temia, era o salário que era muito pouco. Eu achava que ali tinha alguma coisa errada, pois quem trabalhava acima de mim, com dez anos a mais do que eu, só ganhava 10\% a mais. Eu me perguntava: será possível que eu vou ficar aqui tanto tempo pra ganhar só isso? (Entrevista T1 - grifos meus).

O exame dessa situação adquire relevância à luz do que Marx escreveu, em $O$ capital, a respeito dos casos de luta pelo aumento de salários (ou contra sua redução). Dizia ele:

A resistência periódica que os trabalhadores opõem à redução dos salários e suas tentativas periódicas para conseguir um aumento de salários são fenômenos inseparáveis do sistema do salariado e ditadas pelo próprio fato de o trabalho se achar equiparado às mercadorias, por conseguinte submetido às leis que regulam o movimento geral dos preços. (MARX, 1996, p. 113).

Nesse sentido, o trabalhador se verá constantemente em disputa com o empregador para manter de pé o valor de seu trabalho, evitando a tendência de fixação de um limite mínimo. Ainda segundo Marx, se a classe operária renuncia,

a defender-se contra os abusos do capital e abandona seus esforços para aproveitar todas as possibilidades que se lhe ofereçam de melhorar em parte a sua situação [...] ver-se-ia degradada a uma massa informe de homens famintos e arrasados, sem probabilidade de salvação. (MARX, 1996, p. 118).

Ora, o que alguns trabalhadores telefônicos de Curitiba perceberam, naqueles tempos, foi exatamente isso. Ou seja: na ausência de esforços de associação, o poder de resistir e de negociar condições "mais humanas" de trabalho e de salários ficava muito restrito. Era preciso, portanto, "conscientizar" (Entrevista T2) o maior número de colegas de que os baixos vencimentos, os aumentos espontâneos de caráter pessoal e os constantes atritos entre encarregados e empregados mereciam uma reação organizada e oficialmente reconhecida.

A soma de todos esses ingredientes fez com que os primeiros ativistas sentissem a classe telefônica (citada no primeiro discurso de seu líder), ou melhor, aqueles que exerciam tarefas cada vez mais limitadas ao universo do trabalho manual - cabistas, reparadores, instaladores, técnicos de rede, telefonistas, bem como os trabalhadores ainda menos qualificados, ou seja, operários, serventes, guarda-fios, pintores -, sendo empurrada para uma classe única, segregada dos gerentes, supervisores e encarregados-chefe. 


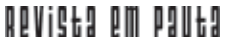

\} A EXPERIÊNCIA HISTÓRICO-CULTURAL - ALMEIDA, I. C. L. \}

DOI 10.12957/REP.2017.30378

Além disso, havia também a segregação entre os mais bem pagos e os menos bem pagos, muitas vezes habitando o mesmo departamento e realizando as mesmas funções. Um sócio fundador do sindicato, aqui identificado como T3, mapeou o quadro da seguinte maneira:

As necessidades salariais e as condições de trabalho, que não tínhamos quase nenhuma, criaram a necessidade de ter um órgão que defendesse os nossos interesses frente à empresa, porque no Paraná não existia. Só pra você saber, tinha chefe que se não gostasse do empregado mandava embora, tinha outros que se gostassem dava aumento de 5\%,10\%, 15\% e até $30 \%$. Então, os aumentos dependiam de uma relação pessoal com a diretoria, mesmo que o empregado fizesse seu trabalho todo certo. $\mathrm{E}$ muitos fizeram trabalhos importantes pra empresa no interior e aqui em Curitiba. Mas tudo dependia da boa vontade da gerência. (Grifos meus).

Mesmo a oportunidade de ascensão era sempre duvidosa e crescentemente diminuída, ou pela inexistência de educação formal, ou pela prática regular da chefia de premiar uns "poucos escolhidos", que ocupavam cargos na empresa. Para os demais, restavam a frustração, a revolta íntima e o amor-próprio ferido, principalmente quando a gerência justificava as diferenças nos reajustes salariais, ou a falta deles, dizendo: "você não merece" (Entrevista T1), sem apresentar qualquer explicação convincente.

Naquela altura, em que se defrontavam também com uma espécie particular de assalariados que atuavam como autoridade da empresa, tornando-se "comandantes industriais" para subordinar a atividade dos demais ao objetivo dela (MARX, 1996), o trabalhador reconheceu a vontade alheia e a apropriação pessoal do cargo pela chefia se sobrepujando aos "critérios profissionais" propriamente ditos, isto é, às atribuições prescritas para as funções do posto de trabalho. Os empregados que se consideravam injustiçados em relação ao arbítrio do comando imediato requeriam a "igualdade de todos perante o direito geral de reajuste e promoção" (Entrevista T3).

Sob tais circunstâncias econômicas e socioculturais, em que, como observou Thompson (1997, p. 10 - grifos meus), "alguns homens, como resultado de experiências comuns (herdadas ou partilhadas), sentem e articulam a identidade de seus interesses entre si, e contra outros homens cujos interesses diferem (e geralmente se opõem) dos seus, é que uma classe acontece" $e^{\prime \prime}$ Nesse caso, somente na medida em que os trabalhadores encontram um sentido para agir em termos não individuais, ou seja, na base de uma noção de identidade coletiva, é que se forma historicamente a classe.

Reportando-se ao ano de 1958, quando a ideia de organizar um sindicato dos trabalhadores telefônicos em Curitiba tomou forma e conteúdo, aqueles que já haviam experienciado reações de grupos profissionais semelhantes em outros estados não lograram fomentar a necessidade de unificar uma série de situações similares, para que houvesse "disposição" dos empregados "de agir" (Entrevista T3) em uma mesma direção. 


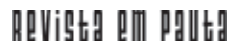

\} A EXPERIÊNCIA HISTÓRICO-CULTURAL - ALMEIDA, I. C. L. \}

DOI $10.12957 /$ REP.2017.30378

A preocupação dos idealizadores do movimento era angariar, em primeira instância, o apoio dos empregados mais antigos da companhia que, assim como eles, possuíam estabilidade na prestação de serviços ao mesmo empregador durante dez anos (BRASIL, 1943), de modo a evitar retaliações administrativas, e cujo grau de confiança era suficiente para assegurar a adesão de um número desejável de colegas.

Olha, os que tinham poucos anos de trabalho, era difícil, né? Eles se negavam porque podia ter uma represália da empresa e o pessoal que tinha cargo, também. Então, não era fácil. Principalmente para os pais de família. [...] No início, para formar os cinquenta e três associados, $O$ pessoal pequeno não tinha medo de assinar a lista, só as pessoas com cargo. E quando nós comecemos a pegar essa gente, eles tinham mais de dez anos, eles tinham estabilidade. Então, pra evitar que uma pessoa fosse perder o serviço por causa do movimento, a gente só tentava pegar associado com estabilidade. Mas muita gente assinou mesmo sem ter, como eu mesmo fiz. (Entrevista T1 - grifos meus).

Ainda que houvesse certa igualdade de condições objetivas às quais todos os trabalhadores assalariados da empresa estavam submetidos, nessa "fase heroica" de organização de interesses em torno de uma associação profissional eram visíveis diferenciações no caráter do trabalho, no estilo de vida, no comportamento político e nas atitudes pessoais. Sem dúvida, aderir ao processo representava um investimento de alto risco, aceito a priori por aqueles que se sentiam mais amparados pela lei e, portanto, menos vulneráveis às ações do patrão.

Desse modo, quase não chega a ser surpreendente que tenha se originado em um "grupo privilegiado", pequeno, relativamente homogêneo, altruísta e disposto a arcar com os custos dessa empreitada o esforço de agregação que exigia, naquele momento, a tolerância como condição essencial, especialmente com os que, embora manifestassem interesse nos resultados da cooperação, resistiam ou por medo ou por acreditarem que outros poderiam fazer em seu lugar.

Segundo Olson (1999, p. 77 - grifo meu), um grupo dessa natureza - em que cada um de seus membros ou pelo menos um deles tem um incentivo para se animar e para fazer com que o benefício coletivo seja obtido, mesmo que ele(s) tenha(m) que suportar sozinho(s) todo o ônus decorrente - se organiza "para uma ação coordenada meramente pelo fato de que, como grupo, tem uma razão para fazê-lo".

Razão que surge orientada para um objetivo claramente formulado e logicamente consistente - a organização sindical. Por meio dela, líderes como S. B. S. ("pessoa muito bemquista, fácil de fazer amizade e bastante respeitada", conforme entrevista do T2) estabeleceram com seus colegas de trabalho uma lealdade de tipo pessoal, que lhes permitiu desempenhar ali um papel-chave: ora selecionando a base social da organização, ora cons- 


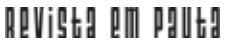

\} A EXPERIÊNCIA HISTÓRICO-CULTURAL - ALMEIDA, I. C. L.

DOI $10.12957 /$ REP.2017.30378

tituindo uma identidade coletiva calcada na predominância, entre a maioria dos empregados, de um sentimento de exclusão social, de despotismo das chefias e de baixos salários.

Até onde se pode notar, a associação - em seu aspecto profissional e solidário - era vista por seus partidários como o primeiro instrumento para a superação daquelas condições socioeconômicas, graças particularmente ao seu caráter elementar de ação reivindicativa coletiva. Tudo isso, no entanto, ensejava um mínimo de representatividade e de poder para constranger o empregador a negociar.

Nessa perspectiva, como conseguir que uma empresa estrangeira, investida oficialmente pelo Estado para atuar no setor de telecomunicações da região de Curitiba e adjacências, reconhecesse a legitimidade desses representantes e passasse a negociar com eles?

Considerando a vivência dos colegas que já haviam participado da formação de um sindicato similar em São Paulo, esses iniciadores entenderam que a criação do sindicato no Paraná só era possível dentro da legalidade oferecida pelo Estado, porque esse desenho institucional escudava juridicamente o empregado diante do poderio da empresa. Assim, instruídos por um funcionário da Delegacia Regional do Ministério do Trabalho, seguiram os passos previstos pela Consolidação das Leis do Trabalho (CLT) e trataram de reunir alguns colegas na Sociedade Estrela da Manhã, no bairro Prado Velho, em Curitiba, para dar andamento ao processo.

A luta pelo "direito de sindicalização" era, na verdade, a luta para que o Estado os colocassem na posição de sentar à mesa de negociação, de serem ouvidos e levados a sério pela companhia. Era o modo de sair da caserna para a rua, convertidos em legítimos representantes dos trabalhadores telefônicos do Paraná. Esses requisitos, sem os quais nenhuma associação ou sindicato podia desempenhar sua função primordial, "o Estado brasileiro outorgava a um único sindicato estabelecido numa dada base territorial a partir de seu reconhecimento oficial" (SIMÃO, 1966, p. 197).

Dominava entre eles a expectativa de que a legalidade concedida pelo Estado seria o passaporte para ingressar no mundo fechado da empresa pela porta da frente e pleitear "salários justos", "respeito" e "dignidade no trabalho". Por esse raciocínio, a associação profissional, instituída em oito de julho de 1958, era algo provisório que deveria ser transformado tão logo quanto possível em sindicato, figura jurídica à qual era destinada a prerrogativa de "representar o conjunto da categoria, solicitar dissídios, firmar convenções ou contrato coletivo" (Entrevista T3).

Vantagens almejadas pelo presidente em exercício, S. B. S., que defendeu, em uma segunda assembleia geral extraordinária realizada em 1958, perante "um terço dos profissionais do ramo da localidade de Curitiba", a urgência na adequação ao Plano de Atividades e Profissões do Ministério dos Negócios do Trabalho, Indústria e Comércio (Art. 577) para dar entrada 


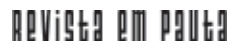

\} A EXPERIÊNCIA HISTÓRICO-CULTURAL - ALMEIDA, I. C. L. \}

DOI 10.12957/REP.2017.30378

na carta sindical do agora denominado Sindicato dos Trabalhadores em Empresas Telefônicas e Radiotelefônicas do Estado do Paraná.

O discurso do presidente pregava a favor da "investidura sindical" (SIMÃO, 1996, p. 197) como um benefício para a categoria, valorizando e aspirando às normas da Justiça do Trabalho e às modalidades de ação que Ihes eram pertinentes. Ademais, a possibilidade de sindicalização era concebida, em regra, como uma atitude coletiva "consciente" em relação ao atomismo e à dispersão anterior.

Em termos jurídicos, conforme salienta Silva (1990), quando grupos profissionais se encarregam da gerência de seus próprios interesses, há, evidentemente, uma tentativa de perseguir dois instrumentos distintos: i) o chamado "Direito de Segurança Social" ${ }^{6}$, em que se instituem pessoas jurídicas de direito público, (co)gerenciadas pelo empregado e pelo empregador, tendo em vista garantir o empregado contra os males do desemprego, doença, velhice, invalidez, acidentes de trabalho e outros; ii) e o "Direito Coletivo do Trabalho"7, no qual o sujeito não é mais o trabalhador, mas sim a categoria que o representa, originando-se um novo sistema de personalismo jurídico, em que os sindicatos atuam como representantes do grupo e não da pessoa.

Com esse último pretende-se afiançar ao empregado a igualdade social e jurídica indispensável para negociar com o empregador, de maneira eficiente, melhores condições de trabalho, sem a dependência e o estado de sujeição que sempre caracterizaram o trabalho subordinado na relação contratual. A formação de sindicatos e de outras modalidades de associações de trabalhadores converte-se, nesses termos, em uma resposta dos trabaIhadores a um espectro de necessidades, que inclui tanto as recompensas materiais quanto a satisfação no trabalho, a saúde, o tempo livre e a continuidade no emprego.

Na especificidade brasileira, como ressalta Füchtner (1980), ainda que a lei tivesse fixado limites mínimos para a operação do mercado de força de trabalho - salário mínimo, idade de entrada e de saída também mínimos e até jornada de trabalho -, do portão da empresa para dentro a estruturação do trabalho e de seu mercado interno sempre foi tida como privilégio do proprietário. Em certo ponto, isso deixava cada empregado (sujeito e objeto da troca da força de trabalho) sob a batuta do regente-empregador.

Ao se reunirem visando ao direito oficialmente adquirido de negociação com a empresa, os empregados da Companhia Telefônica Nacional no Paraná tinham em mente o acesso a estatutos e regras processuais legais em vigor, as quais poderiam, no entendimento deles, sustentar a defesa de

${ }^{6} \mathrm{O}$ Direito de Segurança Social só foi atendido constitucionalmente no Brasil em 5 de outubro de 1988, dentro do título VIII da Ordem Social, em que a seguridade social passa a ser composta pelas áreas da Saúde, Previdência e Assistência Social - Art. 194. Ver: Silva (1990).

${ }^{7}$ O Direito Coletivo do Trabalho foi criado para livrar o empregado do estado de dependência que o instrumento do contrato, em que se centra o Direito Individual do Trabalho, não foi capaz de fazer. 


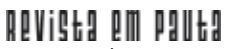

\} A EXPERIÊNCIA HISTÓRICO-CULTURAL - ALMEIDA, I. C. L. \}

DOI 10.12957/REP.2017.30378

suas demandas frente ao patronato e ao próprio Estado. Para o perfil do trabalhador telefônico da época, o "sindicato registrado no Ministério" (Entrevista T1) seria seu único meio de representação, e o Estado, o único interlocutor válido para a consagração dos objetivos, que circunscreviam o âmbito sindical em sua relação com a empresa.

Contudo, até que isso se efetivasse, foi preciso esperar em silêncio; e eles esperaram por dois, três, quatro, cinco meses. Durante esse espaço de tempo, enquanto a associação ia se equilibrando financeiramente com a mensalidade de vinte cruzeiros, cobrada dos sócios fundadores e dos membros que gradativamente se filiavam (ao final do ano de 1958 eram, segundo os relatórios da associação, 162 filiados), seus diretores e associados estiveram várias vezes na Delegacia Regional, no intuito de saber a razão "para tanta demora". Chegaram a contratar uma pessoa para ir ao Rio de Janeiro investigar a situação. Teria a Companhia Telefônica Nacional descoberto tudo e estaria tentando "engavetar", como há dez anos, a iniciativa de seus empregados?

Ignorando o que se passava, de fato, e ansiando pelo sinal oficial que Ihes daria condições de "conversar com a empresa sobre os assuntos dos trabalhadores" (Entrevista T2), eles foram aconselhados por funcionários da Delegacia do Trabalho a buscar uma "ajuda política" (Entrevista T3), recorrendo à figura parlamentar paranaense de maior destaque na ocasião: o Senador Souza Naves.

Eles acharam que nós devia recorrer a um político e o maior político do Paraná naquela época era o Senador Souza Naves. Mas ele ia mais pro Rio do que ficava em Curitiba. Então, a Delegacia do Trabalho informou a nós que ele ia chegar sábado. Não sei como eles souberam, mas nós fomos lá na casa dele, que ficava no Alto da Rua XV. Quando o carro chegou, meio-dia em ponto, estava nós três na calçada, era eu [G. A.], o S. B. S. e o M. G. M., e falemos com ele que a carta tava demorando muito, que a gente não sabia diretamente se era a empresa, mas sabia que tinha alguma coisa que tava dificultando essa carta. E pra formar mesmo o sindicato só com a presença dessa carta [...], porque aí a gente tinha o documento na mão. E ele foi uma pessoa muito eficiente pra nós, na época, porque ele disse assim pra nós: 'Hoje, eu tô aqui, amanhã eu tô no Rio Grande e segunda eu tô no Rio, e verei o caso de vocês'. E aí quando foi na terça-feira, ele telefonou pra Delegacia do Trabalho que a carta já estava indo e que nós aguardasse ela aparecer na Delegacia pra nós pegar. E, na quarta-feira, a carta chegou... (Entrevista T1 - grifos meus).

A imagem transmitida pelo trabalhador da pressão ativa realizada pelo grupo no sentido de obter a carta sindical parece reiterar o princípio sustentado por Cardoso (1999, p. 48) de que "os trabalhadores, ao se organizarem para intervir na realidade brasileira, o fazem por meio da criação do instrumento que é parte do repertório consolidado de mecanismos aglutinadores de interesses no país: os sindicatos 'oficiais'". 


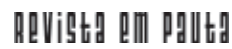

\} A EXPERIÊNCIA HISTÓRICO-CULTURAL - ALMEIDA, I. C. L. \}

DOI $10.12957 /$ REP.2017.30378

No caso dos trabalhadores telefônicos, parecia lógico (como na fala destacada do T1) organizar a categoria criando um sindicato tal como permitido pela legislação existente. Não por acaso, enredaram-se junto à posse do documento duas ações imediatas: o empréstimo de uma sala junto ao Sindicato dos Trabalhadores em Artefatos de Couro para estabelecer, na Praça Zacarias, a sede provisória do Sinttel em Curitiba, e a aproximação com a Federação dos Trabalhadores nas Indústrias do Paraná, entidade que via com bons olhos o estreitamento formal dessa parceria.

Para alívio de seus membros, agora a associação tornada sindicato em 27 de janeiro de 1959 podia, enfim, vestir seu figurino oficial e mostrarse publicamente ao mundo do capital e do trabalho. Afinal, foi desse modo que a legislação os reconheceu, fornecendo os procedimentos - duração, direitos e deveres das partes e resultados - para negociação com a empresa individual. Foi também, desse modo, que eles se reconheceram como agentes representativos de um coletivo de trabalhadores organizado chamado "Sindicato".

\section{Considerações finais}

O conceito de experiência histórica de Thompson, tomado como base para descrever e analisar o processo de (form)ação da classe dos trabaIhadores telefônicos do Paraná entre 1958 e 1959, evidencia as motivações, expectativas e finalidades que conduziram homens e mulheres a constituir um "grupo associativo" - mais tarde transformado em um "sindicato oficial" umbilicalmente ligado ao Estado - dentro de um setor marcado pela presença de interesses internacionais, pelo tenso ambiente que envolvia os dois últimos anos de mandato do Governo Juscelino Kubitschek e dentro da dinâmica de outorga de concessões de serviço público de telecomunicações (órgãos estaduais e municipais) às empresas privadas (principalmente estrangeiras).

O papel da dimensão histórica, nesse contexto, foi o de circunscrever mudanças e contradições internas nas instituições sociais envolvidas, enfatizando o processo ativo por meio do qual os trabalhadores telefônicos paranaenses combinaram experiência e cultura na consolidação e defesa de seus interesses e direitos.

Dimensão que permite adentrar no processo de organização associativa e sindical desses homens e mulheres, percebendo como eles vieram a ocupar um lugar social e político a partir do resgate de suas aspirações e leituras de mundo.

Essas narrativas evidenciam como foram construindo uma identidade entre si (ser social) e uma consciência social (de classe) que lhes proporcionaram formar um quadro político de organização social, a despeito das reivindicações malogradas. 


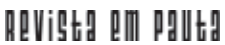

\} A EXPERIÊNCIA HISTÓRICO-CULTURAL - ALMEIDA, I. C. L.

DOI 10.12957/REP.2017.30378

Isso significa dizer que uma conjugação de elementos internos organização, discurso, fundamentos e ação - e de pressões conjunturais, decorrentes da situação social do país e de sua inserção numa nova lógica do capital e do trabalho, na década de 1950, evidenciam também que a configuração política dos trabalhadores telefônicos do Paraná não obedeceu somente a uma necessidade material, econômica.

Portanto, face a face com as turbulências estruturais, os valores, sentimentos, crenças e conhecimentos adquirem importância substancial na explicação do comportamento político desses trabalhadores, das demandas feitas ao sistema, das respostas às leis e das solicitações de suportes protecionistas. Logo, já se faz supor também que, nessa perspectiva, a cultura - conforme ressaltou Thompson (1997) - ocupa uma posição estratégica.

Tendo em vista tais considerações foi que esse estudo de caso procurou seguir a trilha das práticas desses trabalhadores ordenadas no espaço e no tempo histórico e cultural em que se (trans)formaram, recriando suas ações pelos próprios meios pelos quais se expressam como sujeitos e percorrendo o sentido dos conceitos que emergem de suas narrativas como predisposições e orientações articuladas em processos culturais gerais e particulares. Ou, conforme identifica Chartier (1988, p. 16-17), "entre práticas e representações que identificam o modo como em diferentes lugares e momentos uma determinada realidade social é construída, pensada e dada".

Essas representações, articuladas pelos indivíduos para dar sentido ao mundo, para entendê-lo e para nele encontrar o seu lugar, lidam necessariamente com a esfera da construção de valores, crenças, autorrepresentação, representação do mundo e do outro no seio das relações de conflito e de poder. Além disso, também ensejam os elementos essenciais para a construção de uma prática política fundada em um tipo de "solidariedade" gerada por um "consenso intraclasse" intermediado pelo Estado.

É nesse ponto que se percebe a relevância das análises históricoculturais voltadas para a experiência cotidiana e para a ação reflexiva dos sujeitos ao promoverem uma relação mais fluida entre os mundos interno e externo do trabalho, e entre o padrão técnico-produtivo e o simbólico-expressivo do mundo da produção e da reprodução. Ademais, pesquisas dessa natureza permitem compreender as dimensões do tempo, evitando-se a redução mecanicista de estilos de vida ao resultado das pressões sociais.

Permitem tornar inteligível, também, o modo pelo qual, sob pressão das contradições estruturais e da socialização, os trabalhadores criam um fluxo e desenvolvem táticas de seleção em seu potencial identitário.

Em outras palavras, os aspectos culturais são analisados para interrogar como as "classes trabalhadoras" se dotam de sistemas de valores e de universos de sentido, qual é a autonomia desses sistemas e sua contribuição à constituição de uma identidade coletiva, e como se articulam, nas identidades coletivas dos grupos dominados, às dimensões da resistência e de uma aceitação - resignada ou aflita - da subordinação. 


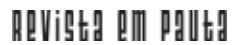

\} A EXPERIÊNCIA HISTÓRICO-CULTURAL - ALMEIDA, I. C. L. \}

DOI $10.12957 /$ REP.2017.30378

O desafio epistemológico posto por esses estudos (e que reside nos efeitos práticos de um conhecimento que é fundamental em ciências sociais) foi realizado por Thompson (1997) em A formação da classe operária inglesa ao dispensar à experiência cotidiana dos trabalhadores, ao longo de períodos históricos, uma atenção minuciosa, compreensiva e crítica da atuação conjunta na defesa de seus direitos, constituindo sua própria "consciência de classe" ou "cultura de classe".

Thompson (1997) tratou, portanto, de captar o sentido das ações humanas a partir dos próprios atos - deliberados ou não - de homens e muIheres que também sofreram a influência das ações passadas e contemporâneas de outros homens e mulheres. No caso dos trabalhadores telefônicos do Paraná, no decurso de um conjunto de experiências concretas e cumulativas que foram se estabelecendo em um período histórico de uma década, tais ações passaram a estimular interesses coletivos e a constituir a expectativa (positiva) de que uma determinada ação coletiva de classe, independentemente do contexto, poderia solucionar, por meio da política sindical, problemas críticos para a classe.

Essa experiência histórica em um contexto econômico, político e cultural específico formou a classe entre 1958 e 1959, mas foi atualizandoa em três momentos subsequentes: entre 1959 e 1967, sob o regime de concessão pública às empresas privadas; entre 1968 e 1998, na era do monopólio estatal; e de 1998 em diante, quando se regulamentou a reprivatização dos serviços de telefonia no país - períodos tratados em pesquisa posterior.

Foi um processo de atualização de classe que, conforme aponta Thompson (2001), materializa-se nas condições objetivas das mudanças sociais e no conjunto de ideais e práticas que reiteram e reinstauram culturalmente uma (re)leitura de mundo. Isso nos coloca também a necessidade de interrogar, em outras condições históricas, sobre o processo por meio do qual os trabalhadores assalariados se adaptam pouco a pouco à empresa e, de um certo modo, acomodam-se a ela. Cabe indagar, também, como esses trabalhadores se apropriam dela e são apropriados por ela; apropriam-se de seu instrumento de trabalho e são apropriados por ele; apropriam-se de suas tradições operárias e são apropriados por elas; apropriam-se de seu sindicato e são apropriados por ele.

Nesse processo (dialético-reflexivo), os trabalhadores tanto podem renunciar às injunções exteriores reais e imaginárias quanto se identificar com a sua posição no campo político de luta, assumindo totalmente os interesses a ele associados sem modificar suas disposições profundas. Ao contrário, também podem modificá-las pelas injunções objetivas do meio industrial, aprendendo as regras de conduta que devem ser respeitadas em matéria de cadências ou de solidariedade. Podem, ainda, para serem aceitos, aderir aos valores coletivos (como o respeito ao instrumento de trabalho), ou mesmo assumir a história coletiva do grupo, suas tradições, suas lutas. 


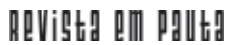

\} A EXPERIÊNCIA HISTÓRICO-CULTURAL - ALMEIDA, I. C. L. \}

DOI 10.12957/REP.2017.30378

Sob essas condições, o campo histórico-cultural mostra-se vasto para a exploração de evidências práticas sobre a validade do modelo de identidade coletiva dos trabalhadores frente às recorrentes transformações do "mundo do trabalho", em especial em países como o Brasil, lócus de processos institucionais, de crises e de reformulação do Estado específicos. Aqui, mudanças na composição da população e das gerações, alterações no estilo de vida individuais e transformações na estrutura política e econômica são consideradas fontes importantes de mudança na cultura (política) do trabalho e das classes trabalhadoras.

Ao investir nesse ponto de vista, pesquisas desse porte permitem refletir acerca do sociocultural como um espaço de competição e de interdependência entre sujeitos, abdicando das velhas dicotomias entre as dimensões objetiva e subjetiva da mudança. Tal reposicionamento teórico e metodológico pode ser percebido como a tentativa de identificar os meios mais profícuos para a análise em campo das articulações entre o contexto e a ação sindical, por exemplo.

Foi com essa intencionalidade que a obra de Thompson tornouse aqui referência para a reconstituição dos fios que enredam a experiência histórica e cultural de formação de classe entre os trabalhadores telefônicos do Paraná; e foi com essa intencionalidade também que a obra de Thompson tornou-se referência para retomar, nesse estudo, o diálogo sempre fecundo entre a história e a sociologia. Ainda mais quando esse diálogo indica que as justificativas para a ação social e política dependem igualmente da legitimação dos aspectos culturais. 


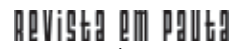

\} A EXPERIÊNCIA HISTÓRICO-CULTURAL - ALMEIDA, I. C. L. \}

DOI 10.12957/REP.2017.30378

\section{Referências}

ALMEIDA, I. C. L. de. Adeus ao sindicato? O sindicalismo diante das transformações no mundo do trabalho: o caso do Setor de Telecomunicações no Paraná. Dissertação (Mestrado) - Programa de Pós-Graduação em Sociologia, UFPR, Curitiba, 2004. Mimeo.

ALTHUSSER, L. Posições 1. Rio de Janeiro: Graal, 1978.

ANTUNES, R. O novo sindicalismo no Brasil. Campinas: Pontes, 1995.

BRASIL. Consolidação das Leis do Trabalho. Decreto-Lei no 5.442, de 01.mai.1943. Disponível em: http://www.planalto.gov.br/ccivil_03/DecretoLei/Del5452compilado.htm. Acesso em: maio.2016.

CARDOSO, A. M. Sindicatos, trabalhadores e a coqueluche neoliberal: a Era Vargas acabou? Rio de Janeiro: Fundação Getúlio Vargas, 1999.

CHARTIER, R. A história cultural: entre práticas e representações. Rio de Janeiro: Bertrand Brasil, 1988.

DIEESE. Departamento Intersindical de Estatísticas e Estudos Socioeconômicos. Os sindicatos e a política econômica do novo governo. Boletim. São Paulo, v. 1, n. 10, 1961.

FÜCHTNER, H. Os sindicatos brasileiros: organização e função política. Rio de Janeiro: Graal, 1980.

IBGE. Instituto Brasileiro de Geografia e Estatística. Anuário estatístico, 1950.

MARX, K. O capital: crítica da economia política. Vol. 1. São Paulo: Nova Cultural, 1996.

OLSON, M. A lógica da ação coletiva. São Paulo: Edusp, 1999.

PALMER, B. E. P. Thompson: objections and opositions. London: Verso, 1994.

SILVA, A. A. da. Pluralismo sindical na nova Constituição. Belo Horizonte: Del Rey, 1990.

SIMÃO, A. Sindicato e Estado. São Paulo: Dominus, 1966.

SINTTEL. Livro de atas de assembleias gerais extraordinárias (1958-1961). Paraná: Sinttel, 1961. Mimeo.

THOMPSON, E. P. A miséria da teoria, ou um planetário de erros: uma crítica ao pensamento de Althusser. Rio de Janeiro: Zahar, 1981.

. A formação da classe operária inglesa: a árvore da liberdade. Rio de Janeiro: Paz e Terra, 1997.

. As peculiaridades dos ingleses e outros artigos. In: NEGRO, A. L.; SILVA, S. (Org.). As peculiaridades dos ingleses e outros artigos. Campinas: Editora da Unicamp, 2001. 
\} A EXPERIÊNCIA HISTÓRICO-CULTURAL - ALMEIDA, I. C. L. \}

DOI 10.12957/REP.2017.30378

Recebido em 27 de julho de 2016.

Aprovado para publicação em 09 de dezembro de 2016.

DOI 10.12957/rep.2017.30378

\section{(c) (1)}

A Revista Em Pauta: Teoria Social e Realidade Contemporânea está licenciada com uma Licença Creative Commons Atribuição 4.0 Internacional.

EM PAUTA, Rio de Janeiro - $1^{\circ}$ Semestre de 2017 - n. 39, v. 15, p. 85 - 105

Revista da Faculdade de Serviço Social da Universidade do Estado do Rio de Janeiro 